\title{
A Study on Clinical Profile of Deviated Nasal Septum and to determine the Efficacy of the Surgery
}

\author{
${ }^{1}$ Mohan Mogarnad, ${ }^{2}$ Vandana Mohta
}

\begin{abstract}
Aim: To study the clinical profile of deviated nasal septum and to assess the subjective efficacy of the surgical outcome using Likert scale.

Materials and methods: This study is a prospective, observational, single-center study from October 2013 to May 2015. The study was conducted in Sri Siddhartha Medical College, Tumkur, Karnataka, India. A detailed clinical history was taken and clinical examination of the patient was carried out. Sixty symptomatic patients were taken up. Patient scored their symptom-related severity using a Likert scale preoperatively. All patients underwent conventional septoplasty. Postoperatively, their symptoms were scored on 30th, 45th, and 90th day.
\end{abstract}

Results: Preoperative and Postoperative values were analyzed. Statistically significant improvement was observed in the entire population: Nasal obstruction $(p<0.001)$, headache $(p<0.001)$, nasal discharge $(p<0.001)$, facial pain $(p<0.001)$, and hyposmia $(p<0.001)$. Patient satisfaction was high and they used fewer nasal medications.

Conclusion: After surgical correction of the septum and analysis of the subjective scale, i.e., Likert scale showed improvement in all symptoms. The principal benefits of septal surgery relate to improvement in nasal symptoms.

Keywords: Clinical profile, Deviated nasal septum, Likert scale, Septoplasty.

How to cite this article: Mogarnad M, Mohta V. A Study on Clinical Profile of Deviated Nasal Septum and to determine the Efficacy of the Surgery. Clin Rhinol An Int J 2017;10(2):70-73.

Source of support: Nil

Conflict of interest: None

\section{INTRODUCTION}

Symptoms and signs accompanying septal pathology may be nasal blockage, dryness, crusting, bleeding, itching, rhinorrhea, anosmia, headache, and cosmetic complaints. These are the common problems faced by otorhinolaryngologists in day-to-day practice.

\footnotetext{
${ }^{1}$ Professor and Head, ${ }^{2}$ Resident

1,2Department of ENT, Sri Siddhartha Medical College, Tumkur Karnataka, India

Corresponding Author: Mohan Mogarnad, Professor and Head, Department of ENT, Sri Siddhartha Medical College Tumkur, Karnataka, India, Phone: +919980037194, e-mail: mmogarnad@yahoo.co.nz
}

Underlying pathology is either a septal deformity or mucosal pathology.

Among these symptoms, common problems are headache and nasal obstruction. Determination of the primary cause can be both challenging and frustrating. However, identification and treatment of patients whose symptoms arise from the sinonasal region is rewarding especially when a correctable anatomic problem, i.e., septal deviation, contributes to the disease process.

Although septoplasty is a common procedure, there have been few studies on the patient-relevant clinical outcomes of nasal septal surgery. Most were retrospective and none used an outcomes instrument validated for nasal symptoms. Despite multiple study methods, however, prior studies have found that septoplasty is generally beneficial. Hence, the present study has been taken up to describe the clinical profile of deviated nasal septum and to determine the efficacy of the surgery using a subjective scale on the patients. Patients rated their symptoms from 0 (not troubled at all) to 6 (extremely troubled) using Likert scale, preoperatively and postoperatively for a stipulated time and thus the subjective improvement was assessed.

\section{MATERIALS AND METHODS}

The present study was on the clinical profile of deviated nasal septum and to determine the efficacy of the surgery that was carried out in the Department of Otorhinolaryngology, Sri Siddhartha Medical College, Tumkur, Karnataka, India, between October 1, 2013, and May 31, 2015.

All patients attending the outpatient Department of Otorhinolaryngology, Sri Siddhartha Medical College, Tumkur, Karnataka, India, with deviated nasal septum who fulfilled the inclusion criteria were included in the study.

Data were collected by selecting the patients with symptomatic deviated nasal septum willing for surgery.

\section{Sample Size}

Sixty patients were included in the study.

\section{Sampling Method}

Convenience sampling 


\section{Study Design}

Prospective study

\section{Inclusion Criteria}

Patients with symptomatic deviated nasal septum between 15 and 60 years.

\section{Exclusion Criteria}

Nasal obstruction due to tumor, polyp, and allergic rhinitis

Revision surgery

Septoplasty in combination with sinus and other surgeries

Rhinoplasty operation

Patients who did not return for follow-up

\section{Methods of Collection of Data}

Cases selected for the study were subjected to detailed history and clinical examination.

- They were assessed subjectively and objectively before the surgery.

- Nasal patency test was done followed by anterior rhinoscopy and details were noted.

- Deviations were classified according to Mladina classification, which was modified by Rao et al (Fig. 1):

- Type I: Mild deviation in vertical or horizontal plane

- Type II: Moderate anterior vertical deviation of cartilaginous septum in full length

- Type III: Posterior vertical deviation at level osteomeatal complex and middle turbinate

- Type IV: "S" shaped, posterior to one side and anterior to other

- Type V: Horizontal septal crest touching or not touching the lateral wall

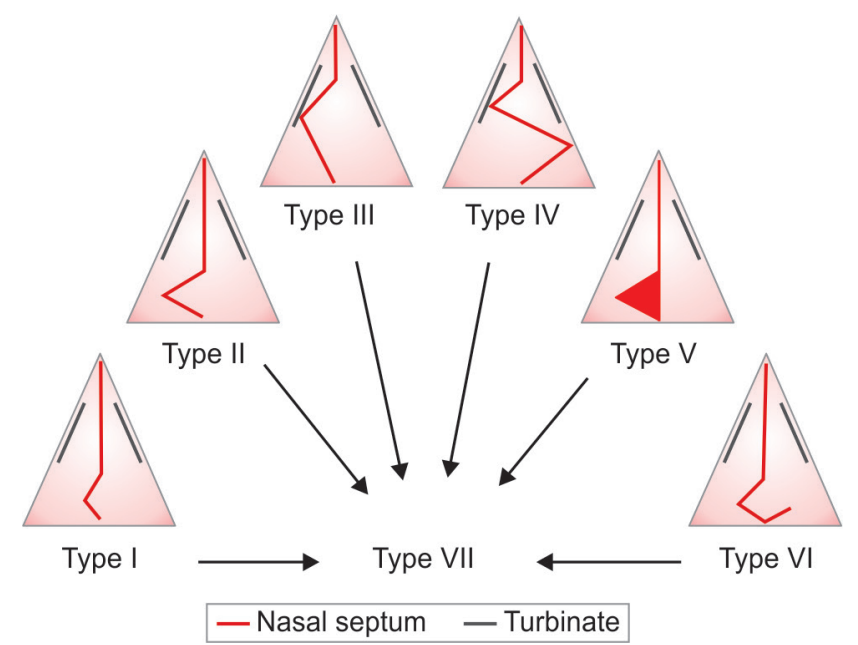

Fig. 1: Mladina classification modified by Rao et al
- Type VI: Prominent maxillary crest contralateral to the deviation with a septal crest to the deviated side

- Type VII: Combination of previously described septal deformity types

- Posterior rhinoscopy was done in all patients to rule out other pathologies.

- X-ray nose and paranasal sinus was done (Water's view) in all the cases.

- Computed tomography scan of paranasal sinuses was done in selected cases.

- Diagnostic nasal endoscopy was performed.

- A correlation was established between clinical features and endoscopic findings.

- After complete preoperative assessment, patients were subjected to surgical intervention.

\section{RESULTS}

In our study of 60 cases, $40(67 \%)$ patients were male and $20(33 \%)$ patients were female, in a ratio of 2:1 male to female. The age of the patients varied between 17 and 45 years, and the mean age was 29.3 years (Table 1 ). In our study, all 60 patients (100\%) had presented with nasal obstruction. The next common symptom was headache in 51 patients $(85 \%)$, followed by nasal discharge in 44 patients $(73 \%)$, facial pain in 18 patients $(30 \%)$, and hyposmia in 3 patients (5\%). There were no patients who presented with epistaxis (Table 2).

Following are the anterior rhinoscopy findings where deviated nasal septum was present in all the 60 patients. In 21 patients (35\%), the nasal mucosa was congested. Thirty-four patients (56.6\%) had right-sided deviation, 26 patients (43.3\%) had left-sided deviation, 11 patients (18.3\%) had spur, and 44 patients (73.3\%) had inferior turbinate hypertrophy on the opposite side (Table 3 ). Following are the diagnostic nasal endoscopy findings

Table 1: Age distribution pattern among the study group

\begin{tabular}{lll}
\hline Age (years) & Number of patients & $\%$ \\
\hline $11-20$ & 11 & 18.3 \\
$21-30$ & 25 & 41.7 \\
$31-40$ & 20 & 33.3 \\
$41-50$ & 4 & 6.7 \\
$51-60$ & 0 & 0 \\
\hline
\end{tabular}

Table 2: Presenting symptoms of the study group

\begin{tabular}{lll}
\hline Symptoms & Number of patients & $\%$ \\
\hline Nasal obstruction & 60 & 100 \\
Headache & 51 & 85 \\
Nasal discharge & 44 & 73 \\
Facial pain & 18 & 30 \\
Hyposmia & 3 & 5 \\
Epistaxis & 0 & 0 \\
\hline
\end{tabular}


Table 3: Anterior rhinoscopy finding

\begin{tabular}{lll}
\hline Findings & Number of patients & $\%$ \\
\hline Septal deviation & 60 & 100 \\
Right & 26 & 43.3 \\
Left & 34 & 56.7 \\
Inferior turbinate hypertrophy & 38 & 63.3 \\
Congested mucosa & 21 & 35 \\
Spur & 11 & 18.3 \\
External deformity & 8 & 13.3 \\
\hline
\end{tabular}

Table 5: Septal deformities seen in the study group according to Mladina classification modified by Rao et al

\begin{tabular}{lll}
\hline $\begin{array}{l}\text { Mladina classification } \\
\text { modified by Rao et } \text { al }^{3}\end{array}$ & $\begin{array}{l}\text { Number of } \\
\text { patients }\end{array}$ & $\%$ \\
\hline Type I & 2 & 3.3 \\
Type II & 7 & 11.67 \\
Type III & 4 & 6.67 \\
Type IV & 8 & 13.3 \\
Type V & 19 & 31.67 \\
Type VI & 14 & 23.3 \\
Type VII & 6 & 10 \\
\hline
\end{tabular}

done using $0^{\circ}$ nasal endoscope (Table 4). In the study, all 60 patients were classified according to Mladina classification which was modified by Rao et al (Table 5). Postoperative patients were reviewed on 30th, 45th, and 90th day. During each visit, patients were asked about their symptomatic improvement and benefits of the surgery and scoring was tabulated (Graph 1).

\section{DISCUSSION}

In the present study, there are $40(67 \%)$ males and number of female patients are $20(33 \%)$, in the ratio of 2:1. Our findings correlate with those of Satish and Sreedhar, where out of 70 patients, 48 patients $(68.6 \%)$ were males and 22 patients $(31.4 \%)$ were females in their study in the ratio 2.1:1.

In the present study, the age group of the patients included was between 17 and 60 years. The youngest patient was 17 years old while the eldest was 45 years old. The mean age was 29.3 years. Highest number of patients belonged to group between 21 and 30 years, i.e., 25 patients $(41.7 \%)$, next between 31 and 40 years, i.e., 20 patients (33\%). Nayak et $\mathrm{al}^{2}$ concluded that the mean age of patients in their study was 28 years, which is similar to our study. Most of the patients belonged between second and fourth decade of life in a study conducted by Rao et al, ${ }^{3}$ which is comparable to our study.

In our study, the common symptom was nasal obstruction $(100 \%)$, followed by headache $(85 \%)$, nasal discharge $(73 \%)$, facial pain $(30 \%)$, and hyposmia (5\%). The finding of the present study was similar to a study conducted by Iqbal et $\mathrm{al}^{4}{ }^{4}$ which concluded that nasal
Table 4: Diagnostic nasal endoscopic findings

\begin{tabular}{lll}
\hline Findings & Number of patients & $\%$ \\
\hline Septal deviation & 60 & 100 \\
Inferior turbinate hypertrophy & 38 & 63.3 \\
Congested mucosa & 21 & 100 \\
Spur & 11 & 35 \\
Discharge in osteomeatal & 10 & 16.6 \\
complex & & 10 \\
Presence of accessory ostia & 6 & \\
\hline
\end{tabular}

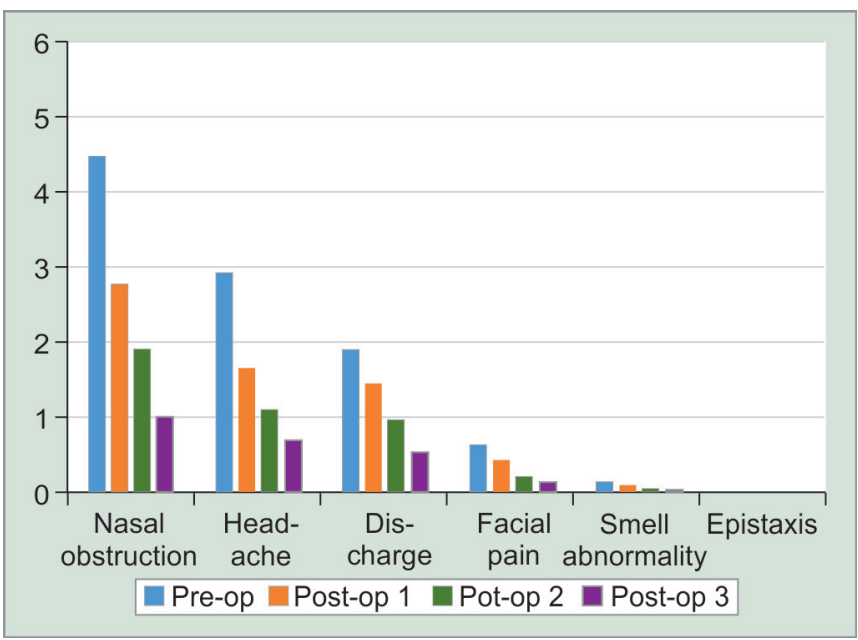

Graph 1: Mean preoperative and postoperative symptom score

obstruction was present in 220 patients (100\%). Another study conducted by Bothra and Mathur ${ }^{5}$ showed that nasal obstruction was the most common presenting symptom found in $90 \%$ of the patients.

In a similar study conducted by Mladina et $\mathrm{al}^{6}{ }^{6}$ leftside deviation (51.6\%) was more common than right-side deviation $(48.4 \%)$, which is similar to the present study. In a study by Sam et $\mathrm{al}^{7}$ they concluded that inferior turbinate hypertrophy was present in $55 \%$ of patients of deviated nasal septum, which is comparable to our study where inferior turbinate hypertrophy was present in $63.3 \%$ of patients.

Like in the present study where most number of patients belonged to types V and VI, Rao et $\mathrm{al}^{3}$ concluded that $63 \%$ of patients belonged to types V and VI where horizontal crest touches or not touches the lateral wall and there is prominent maxillary crest contralateral to the deviation with septal crest to the deviated side. A study conducted by Sam et $\mathrm{al}^{7}$ noted that accessory ostia was present in $8 \%$ of the patients, which is similar to the present study.

In the present study, statistically significant improvement was observed in the entire patient population with respect to the six clinical outcome measures. Statistical analysis was done using Wilcoxon signed rank test: Nasal obstruction ( $p<0.001)$, headache ( $<<0.001)$, nasal discharge $(\mathrm{p}<0.001)$, facial pain $(\mathrm{p}<0.001)$, and hyposmia $(\mathrm{p}<0.001)$. 
Gandomi et $\mathrm{al}^{8}$ concluded that there was a significant improvement in mean nasal obstruction symptom evaluation score after 3 months after septoplasty. The p-value was $<0.001$ for nasal obstruction and hyposmia/anosmia, which is comparable to the present study. Stewart et $\mathrm{al}^{9}$ concluded that patients with nasal obstruction and septal deformity who undergo nasal septoplasty have very significant improvement in nasal obstruction ( $p$-value $<0.0001$ at 3 months), which is similar to the present study. In a study by Satish and Sreedhar, majority of patients who underwent septoplasty showed marked improvement in disease-specific symptoms, good quality of life (QOL), satisfaction, and decreased medication use. Severe preoperative nasal obstruction indicated a higher predicted improvement, $p$-values being $<0.0001,<0.0002$, $<0.0001$, and $<0.0001$ for nasal obstruction, loss of smell or taste, nasal discharge, and facial pain respectively. In a similar study conducted by Reddy-Kolanu, ${ }^{10}$ all the patients who replied to the questionnaire stated that the outcome of the surgery was satisfactory or more than satisfactory. Ninety percent felt that septoplasty was the correct procedure to address their complaint of nasal blockage. In a study conducted by Arunachalam et al, ${ }^{11}$ 200 patients undergoing septal surgery used the Fairley nasal symptom score, the Nottingham health profile, a general health questionnaire, and clinical examination of nasal cavities to assess the outcome. Analysis of the outcomes in the 121 who attended the review patients revealed significant improvement in (a) nasal obstruction in $74 \%$, facial pain in $72 \%$, and catarrh in $64 \%$ of patients; p-value $<0.001$ for nasal obstruction, nasal discharge, and facial pain. Schwentner et $\mathrm{al}^{12}$ found a significant improvement in nasal symptoms, sleep, practical problems, and overall medical state. They concluded that nasal septal surgery creates a lasting impact on patients' diseasespecific QOL. Harley et $\mathrm{al}^{13}$ concluded that surgical correction of anatomic abnormalities of the septum and turbinate, particularly contact points, resulted in predictable improvement in patient-relevant outcome measures with regard to headache severity and frequency, nasal obstruction and level of patient frustration, irritability, and restlessness. Statistically significant improvements were observed in the entire population, headache $(\mathrm{p}<0.001)$, facial pain $(\mathrm{p}<0.01)$, and nasal obstruction $(\mathrm{p}<0.01)$.

\section{CONCLUSION}

Most patients in the study were refractory to medical therapy. We found that surgical correction of obvious anatomic deviation can significantly improve several clinical features including nasal obstruction, headache, facial pain, and nasal discharge.
Strengths of this study are its prospective design, use of validated subjective scale, and patient-based outcome assessment. The study also had a good follow-up rate.

This study shows that for an intervention to be valuable, it should have not only statistical significance but also clinical significance.

Bias regarding the different surgical skills and techniques was removed by performing the surgery using the conventional instruments and method and operation by two surgeons only.

Probable weaknesses of the study are no control group and short follow-up period. As there is no alternative treatment modality for deviated septum other than surgical correction, randomization was not done in our study.

\section{REFRENCES}

1. Satish HS, Sreedhar KT. Septoplasty outcome using SNOT-22 questionnaire study. IOSR J Dent Med Sci 2013 May-Jun;6(5): 34-38.

2. Nayak DR, Balakrishnan R, Murthy KD. An endoscopic approach to the deviated nasal septum - a preliminary study. J Laryngol Otol 1998 Oct;112(10):934-939.

3. Rao JJ, Kumar VEC, Ram Babu K, Chowdary SV, Singh J, Rangamani VS. Classification of nasal septal deviation relation to sinonasal pathology. Indian J Otolaryngol Head Neck Surg 2005 Jul-Sep;57(3):199-201.

4. Iqbal K, Khan MI, Amanullah A. Submucous resection vs septoplasty: complications and functional outcome in adult patients. Gomal J Med Sci 2011 Jan-Jun;9(1):23-27.

5. Bothra R, Mathur NN. Comparative evaluation of conventional vs endoscopic septoplasty for limited septal deviation and spur. J Larynogol Otol 2009 Jul;123(7):737-741.

6. Mladina R, Cujik E, Subaric M, Vukovic K. Nasal septal deformities in ear, nose and throat patients: an international study. Am J Otolaryngol 2008 Mar-Apr;29(2):75-82.

7. Sam A, Deshmukh PT, Patil C, Jain S, Patil S. Nasal septla deviation and external deformity: A correlative study of 100 cases. Indian J Otolaryngol Head Neck Surg 2012 OctDec;64(4):312-318.

8. Gandomi B, Bayat A, Kazemei T. Outcomes of septoplasty in young adults: the nasal obstruction septoplasty effectiveness study. Am J Otolaryngol 2010 May-Jun;31(3):189-192.

9. Stewart MG, Smith TL, Weaver EM, Witsell DL, Yueh B, Hannley MT, Johnson JT. Outcomes after nasal septoplasty: results from the Nasal Obstruction Septoplasty Effectiveness (NOSE) study. Otolaryngol Head Neck Surg 2004 Mar;130(3):283-290.

10. Reddy-Kolanu GR. Patient views on information given before septoplasty, their expectations and outcomes. Darlington County Med J 2009/2010;3(2):30-32.

11. Arunachalam PS, Kitcher E, Gray J, Wilson JA. Nasal septal surgery: evaluation of symptomatic and general health outcomes. Clin Otolaryngol 2001 Oct;26:367-370.

12. Schwentner I, Dejakum K, Schmutzhard J, Deibl M, Sprinzl GM.. Does nasal septal surgery improve quality of life? Acta Otolaryngol 2006 Jul;126(7):752-757.

13. Harley DH, Powitzky ES, Duncavage J. Clinical outcomes for the surgical treatment of sinonasal headache. Otolaryngol Head Neck Surg 2003 Sep;129(3):217-221. 